\title{
Implementação e otimização de projeto para certificação do MDL em estação de tratamento de águas residuárias
}

\section{Implementation and optimization project for CDM certification in wastewater treatment plant}

\author{
Welitom Ttatom Pereira da Silva \\ Doutorando em Tecnologia Ambiental e Recursos Hídricos pelo Programa de Pós-graduação em Tecnologia Ambiental e Recursos Hídricos da \\ Universidade de Brasília (PTARH/UnB) - Brasília (DF), Brasil. Professor Assistente do Departamento de Engenharia Sanitária e Ambiental da \\ Universidade Federal de Mato Grosso - Cuiabá (MT), Brasil.
}

\section{Anaxsandra da Costa Lima Duarte}

Doutoranda em Tecnologia Ambiental e Recursos Hídricos pelo PTARH/UnB - Brasília (DF), Brasil. Professora Assistente do Centro de Ciências Agrárias, Ambientais e Biológicas da Universidade Federal do Recôncavo da Bahia - Cruz das Almas (BA), Brasil.

\section{Marco Antonio Almeida de Souza}

PhD em Engenharia Ambiental pela Universidade de Birmingham - Birmingham, Inglaterra. Professor e Pesquisador Colaborador do PTARH/UnB - Brasilia (DF), Brasil.

\section{Resumo}

O tratamento de águas residuárias pode ser um importante contribuinte para o acúmulo de gases de efeito estufa (GEE) na atmosfera. Com o objetivo de minimizar esse problema, estudou-se a implementação de um projeto de mecanismo de desenvolvimento limpo (MDL) em uma estação de tratamento de esgoto (ETE), mais especificamente a ETE Brasília Norte, por meio de mínimas modificações e otimização de parâmetros operacionais. A metodologia utilizada incluiu a investigação de alternativas para implantação de projetos de MDL em ETE, a análise do fluxograma da ETE, a modelagem matemática e a otimização do processo. Foram concebidos cenários operacionais da ETE, variando a eficiência de tratamento de DBO. Os resultados indicaram uma contradição entre o incentivo à sustentabilidade pelos projetos MDL e a qualidade do efluente tratado.

Palavras-chave: projeto MDL; otimização; créditos de carbono; águas residuárias.

\begin{abstract}
Wastewater treatment can produce an important contribution to greenhouse effect gases accumulation in the atmosphere. With the objective of minimizing this problem, this work studied the implementation and operational optimization of clear development mechanisms (CDM) in a wastewater treatment plant (WWTP), more precisely at the sewage treatment plant of North Brasilia, by applying minimal modifications and optimizing its operation parameters. The work methodology included review of CDM projects implantation alternatives, analysis of the flow diagram of the WWTP, mathematic modeling and process optimization. Some operation scenarios for the WWTP were constructed, with different BOD treatment efficiencies. The results indicate a contradiction between sustainability encouragement by CDM projects and quality of the WWTP treated effluent.
\end{abstract}

Keywords: CDM project; optimization; carbon credit; sewage.

\section{Introdução}

O crescimento populacional ocasionou maior consumo de energia, sobretudo da proveniente da queima de combustíveis fósseis.
Em consequência, foi observada a duplicação da concentração de gases de efeito estufa (GEE) na atmosfera durante o período de 1750 a 1998 (ROCHA, 2003). Atualmente, a comunidade científica vem alertando para a contribuição dos GEE sobre o aumento da

Endereço para correspondência: Welitom Ttatom Pereira da Silva - Universidade de Brasília/UnB - Departamento de Engenharia Civil e Ambiental - Secretaria da Pós-Graduação em Tecnologia Ambiental e Recursos Hídricos - Prédio SG-12, Térreo - Campus Universitário, Asa Norte - 70910-900 - Brasília (DF), Brasil - E-mail: wttatom@terra.com.br Recebido: 03/05/10 - Aceito: 08/03/12 - Reg. ABES: 07710 
temperatura média mundial, levando a um risco a todo o equilíbrio ecológico e à existência do ser humano. Cabe mencionar que há estudos contrários à contribuição dos GEE para o aumento da temperatura média mundial. Um exemplo é o desenvolvido por Koutsoyiannis et al. (2008), em que os autores questionam a validade dos modelos climáticos utilizados para realização de previsões. Segundo os autores, os grandes erros dos modelos climáticos mostram que a eficiência para previsão é muito pobre, o que leva a previsões e possíveis relações entre as variáveis não credíveis (KOUTSOYIANNIS et al., 2008).

O Protocolo de Quioto menciona o Mecanismo de Desenvolvimento Limpo (MDL) como dispositivo de flexibilidade concebido para a participação de países emergentes, prometendo incentivar o desenvolvimento sustentável e, ao mesmo tempo, auxiliar esses países a cumprirem parte de suas metas de redução de emissões de GEE (LIBORIO, 2005). O MDL oferece aos países emergentes a possibilidade de se beneficiarem economicamente dos projetos de redução de emissões, os quais darão origem aos chamados "créditos de carbono", que são basicamente toneladas de $\mathrm{CO}_{2}$ que deixam de ser emitidas ou são retiradas da atmosfera, e que podem ser negociados no mercado mundial. Para que um projeto seja elegível dentro das regras do MDL, há necessidade de atendimento a aspectos que, segundo Carbono Brasil (2006), incluem:

1. Adicionalidade - um projeto é adicional quando realmente contribui para a redução das emissões de gases do efeito estufa. Para isso é traçada uma linha de base (baseline) na qual é determinado um cenário demonstrando o que aconteceria se a atividade do projeto não acontecesse. A partir da linha de base, pode-se determinar a adicionalidade;

2. Validação - a contribuição para o desenvolvimento sustentável de cada projeto deve ser avaliada pela Autoridade Nacional Designada (no caso do Brasil, é a Comissão Interministerial de Mudança Global do Clima, presidida pelo Ministério da Ciência e Tecnologia). Desta avaliação obtém-se um projeto validado;

3. Registro do documento de concepção do projeto na ONU - documentos de auxílio para a apresentação de todas as informações que devem estar contidas neste projeto;

4. Implantação do projeto - é basicamente a execução do projeto;

5. Verificação - revisão periódica das reduções monitoradas das emissões de gases do efeito estufa;

6. Certificação do desempenho - garantia escrita de que a atividade atingiu as reduções de emissões propostas, num determinado período de tempo. No Brasil, um dos maiores projetos de MDL refere-se à captura de $\mathrm{CH}_{4}$ em aterro sanitário, implementado no aterro sanitário Bandeirantes, entre os maiores do país. Com o objetivo de explorar o gás produzido para gerar eletricidade, foram realizadas adequações no sistema de captura dos gases e a instalação de geradores (UNFCCC, 2010). Informações complementares acerca de projetos MDL podem ser encontradas nos sites do United Nations Framework Convention on Climate Change (http://unfccc.int/2860.php) e no site do Ministério da Ciência e Tecnologia (http://www.mct.gov.br/index.php/content/view/4007.html).

O tratamento das águas residuárias pode contribuir para o acúmulo dos GEE por meio da produção de $\mathrm{CH}_{4}$ e $\mathrm{CO}_{2}$, provenientes dos processos de tratamento ou da produção de energia elétrica necessária para a efetivação do processo de tratamento. $\mathrm{O} \mathrm{CH}_{4}$ gerado a partir de tratamento das águas residuárias constituiu cerca de $5 \%$ das fontes globais de metano (EL-FADEL; MASSOUD, 2001). Segundo Thorneloe et al. (2002), o aproveitamento desses gases representa uma opção potencial para redução das emissões de GEE, além de ter ligações com outros setores que somam oportunidades de redução na emissão de GEE. Com o intuito de contribuir para a solução da problemática apresentada, propôs-se estudar a implementação de um projeto MDL numa estação de tratamento de esgoto (ETE), mais especificamente o estudo de caso da ETE Brasília Norte, por meio de mínimas modificações e da otimização de parâmetros operacionais. Especificamente, objetiva-se propor uma alternativa de implantação de projeto MDL com mínimas modificações na ETE Brasília Norte; modelar matematicamente o sistema; e determinar os valores ótimos dos parâmetros operacionais relacionados, para obtenção do máximo de reduções das emissões dos GEE.

\section{Metodologia}

Para a realização deste trabalho, propôs-se o desenvolvimento das seguintes etapas: (1) investigação das alternativas para implantação de projeto MDL; (2) descrição e análise do fluxograma da ETE; (3) modelagem matemática do sistema; e (4) otimização do processo e extração de parâmetros ótimos operacionais. Partindo do princípio de que cada ETE é única e, como tal, representante de um sistema único (processos de tratamento; limitações físicas, químicas e biológicas; etc.) e que cada sistema requer uma modelagem matemática específica, faz-se necessário selecionar um estudo de caso para desenvolvimento da metodologia proposta. Neste estudo, adotou-se o caso da ETE Brasília Norte (ETEB-Norte), localizada na cidade de Brasília (DF) e que atende as seguintes localidades: Asa Norte, Vila Planalto, parte da área central de Brasília, Lago Norte e Vila Varjão.

\section{Etapa 1: Investigação de alternativas para implantação de projetos MDL}

O objetivo desta etapa foi buscar informações sobre projetos de MDL e opções que atendem os aspectos para a certificação dos créditos de carbono, apresentados na introdução. Esta etapa consistiu 
a realização de consulta às informações disponibilizadas pelo United Nations Framework Convention on Climate Change (UNFCCC, 2008) e pelo Ministério da Ciência e Tecnologia (MCT-PNMC-MDL, 2009). Foram pesquisados trabalhos correlatos ao tema de implantação e otimização de projetos MDL em resíduos de saneamento. efluentes pressupõem o conhecimento dos processos físicos, químicos e biológicos envolvidos na ETEB-Norte. Para o caso, foram utilizados modelos já reconhecidos para a representação dos processos e fenômenos envolvidos (Tabela 1) bem como experiências anteriores e trabalhos correlatos ao tema MDL.

\section{Etapa 2: Análise do fluxograma da estação de tratamento de efluentes (ETEB-Norte)}

Nesta fase, buscaram-se oportunidades de reduzir emissões de carbono via comparação das condições físicas e operacionais da ETEB-Norte com alternativas já estabelecidas para implantação de projeto MDL. Assim, adotou-se como processo de análise do fluxograma a busca por essas oportunidades de redução de emissões em cada uma das unidades de tratamento, tendo as etapas de tratamento como regra de sistematização.

\section{Etapa 3: Modelagem matemática}

A Figura 1 ilustra o modelo adotado para o cálculo da redução de emissões de carbono, seguindo o sugerido pela UNFCCC (2009c). As etapas a serem consideradas para a avaliação das emissões de $\mathrm{CO}_{2}$ e as relações existentes entre essas emissões, os processos, as rotinas operacionais e a variação das características dos

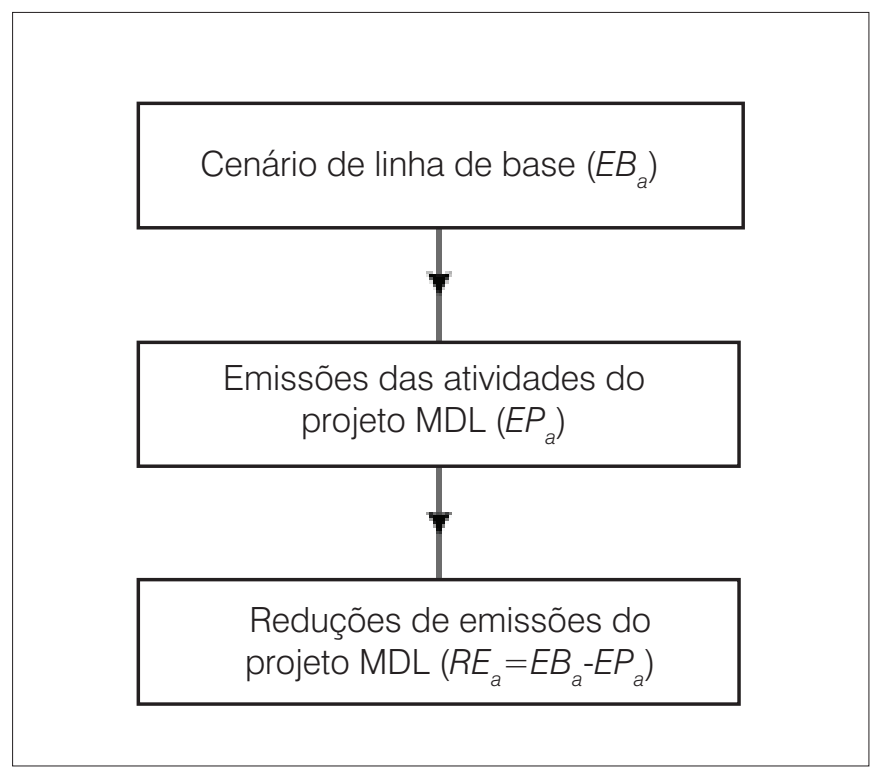

Figura 1 - Modelo adotado para representação das reduções de emissões do projeto MDL.

Tabela 1 - Descrição dos modelos matemáticos utilizados na modelagem.

\begin{tabular}{|c|c|c|c|c|c|c|c|}
\hline Modelos matemáticos & Símbolos e Unidades & Descrição de termos & Co & $\mathrm{Li}$ & Ls & Referência & Equação \\
\hline \multirow{4}{*}{$\begin{aligned} R O_{d}= & \left(1,46 \times \mathcal{Q}_{\text {bruto }} \times D B O_{\text {removida }} \times 10^{-3}\right. \\
& \left.-1,42 \times L_{R A}\right)\end{aligned}$} & $\mathrm{ROd}\left(\mathrm{tO}_{2} \cdot \mathrm{d}^{-1}\right)$ & $\begin{array}{l}\text { Requisito de oxigênio na Estação de } \\
\text { Tratamento de Esgoto, por dia d }\end{array}$ & & & & \multirow[t]{4}{*}{$\begin{array}{l}\text { Von Sperling } \\
\text { (1997) }\end{array}$} & \multirow[t]{4}{*}{ (1) } \\
\hline & $\mathrm{Q}_{\text {bruto }}\left(\mathrm{m}^{3} \cdot \mathrm{d}^{-1}\right)$ & Vazão média do afluente bruto & 45.357 & & & & \\
\hline & $\mathrm{DBO}_{\text {removida }}\left(\mathrm{g} \cdot \mathrm{m}^{-3}\right)$ & $\begin{array}{l}\text { Concentração Demanda bioquímica de } \\
\text { oxigênio removida }\end{array}$ & 183 & 273 & 294 & & \\
\hline & $L_{R A}\left(k g \cdot d^{-1}\right)$ & $\begin{array}{l}\text { Massa de sólidos suspensos voláteis } \\
\text { produzida no reator aerado por dia }\end{array}$ & & & & & \\
\hline \multirow{3}{*}{$\mathcal{Q}_{e x}=V_{R A} \times \theta_{c}^{-1}$} & $Q_{e x}\left(m^{3} \cdot d^{-1}\right)$ & Vazão de descarte de lodo & & & & \multirow{3}{*}{$\begin{array}{l}\text { Von Sperling } \\
\text { (1997) }\end{array}$} & \multirow[t]{3}{*}{ (2) } \\
\hline & $\mathrm{V}_{\mathrm{RA}}\left(\mathrm{m}^{3}\right)$ & Volume do reator aerado & 3.768 & & & & \\
\hline & $\theta_{c}(d)$ & Idade do lodo & 7 & 4 & 10 & & \\
\hline \multirow{2}{*}{$\mathcal{Q}_{r e}=R \times \mathcal{Q}_{\text {bruto }}$} & $Q_{r e}\left(m^{3} \cdot d^{-1}\right)$ & Vazão de recirculação de lodo & & & & \multirow{2}{*}{$\begin{array}{l}\text { Von Sperling } \\
\text { (1997) }\end{array}$} & \multirow[t]{2}{*}{ (3) } \\
\hline & $\mathrm{R}$ & Razão de recirculação & & & & & \\
\hline \multirow[t]{5}{*}{$\begin{aligned} E B_{a} & =\left(E B_{\text {energia }, a}+E B_{e f, \text { tratamento }, a}\right. \\
& +E B_{l, \text { tratamento }, a}+E B_{e f, \text { desc arg } a, a} \\
& \left.+E B_{l, \text { disposicäo }, a}\right)\end{aligned}$} & $\mathrm{EB}_{\text {energia,a }}\left(\mathrm{tCO}_{2} \mathrm{e}\right)$ & $\begin{array}{l}\text { Emissões da quantidade consumida de } \\
\text { eletricidade ou diesel no ano a - no caso, } \\
\text { será nula, uma vez que a fonte de energia } \\
\text { é de baixo custo }\end{array}$ & & & & \multirow[t]{5}{*}{$\begin{array}{l}\text { UNFCCC } \\
\text { (2009c) }\end{array}$} & \multirow[t]{5}{*}{ (4) } \\
\hline & $\mathrm{EB}_{\text {ef,tratamento,y }}\left(\mathrm{tCO}_{2} \mathrm{e}\right)$ & $\begin{array}{l}\text { Emissões do sistema de tratamento de } \\
\text { efluentes no ano a - no caso, será nula } \\
\text { (sistema aeróbio é bem operado) }\end{array}$ & & & & & \\
\hline & $\mathrm{EB}_{1, \text { tratamento,a }}\left(\mathrm{tCO}_{2} \mathrm{e}\right)$ & Emissões do tratamento do lodo no ano a & & & & & \\
\hline & $\mathrm{EB}_{\text {ef,descarga,a }}\left(\mathrm{tCO}_{2} \mathrm{e}\right)$ & $\begin{array}{l}\text { Emissões da matéria orgânica residual do } \\
\text { efluente tratado no ano a }\end{array}$ & & & & & \\
\hline & $\mathrm{EB}_{1, \text { disposição,a }}\left(\mathrm{tCO}_{2} \mathrm{e}\right)$ & $\begin{array}{l}\text { Emissões da matéria orgânica residual } \\
\text { do lodo no ano a - no caso, será nula, } \\
\text { uma vez que o lodo será utilizado como } \\
\text { condicionador do solo }\end{array}$ & & & & & \\
\hline
\end{tabular}

*Equação obtida a partir do ajuste de um modelo empírico aos dados encontrados por diversos autores e apresentados por Jordão e Pessôa (2005) (ajuste satisfatório, $\mathrm{R}^{2}=0$,829) Co: constante; Li: limite inferior; Ls: limite superior. 
Tabela 1 - Descrição dos modelos matemáticos utilizados na modelagem (continuação).

\begin{tabular}{|c|c|c|c|c|c|c|c|}
\hline Modelos matemáticos & $\begin{array}{l}\text { Símbolos e } \\
\text { Unidades }\end{array}$ & Descrição de termos & Co & Li & Ls & Referência & Equação \\
\hline \multirow{7}{*}{$\begin{aligned} E B_{L, \text { tratamento, } a} & =\sum_{j}\left(L_{j, C B, a} \times F M C_{l, \text { tratament }}\right. \\
& \times C O B_{l} \times F C_{C B} \times C O B_{F} \\
& \left.\times F \times 16 / 12 \times P A Q_{C H 4}\right)\end{aligned}$} & $\mathrm{L}_{\mathrm{j}, \mathrm{CB}, \mathrm{a}}(\mathrm{t})$ & $\begin{array}{l}\text { Quantidade de lodo seco tratado pelo } \\
\text { sistema de tratamento de lodo j }\end{array}$ & & & & \multirow[t]{7}{*}{$\begin{array}{l}\text { UNFCCC } \\
(2009 \mathrm{c})\end{array}$} & \multirow[t]{7}{*}{ (5) } \\
\hline & $\mathrm{FMC}_{\text {Itratamento, CB,j }}$ & $\begin{array}{l}\text { Fator de correção de metano no sistema } \\
\text { de tratamento de lodo j }\end{array}$ & 0,80 & & & & \\
\hline & $\mathrm{COB}_{1}$ & $\begin{array}{l}\text { Conteúdo biodegradável do lodo gerado } \\
\text { no ano a }\end{array}$ & 0,50 & & & & \\
\hline & $\mathrm{FC}_{\mathrm{CB}}$ & $\begin{array}{l}\text { Fator de correção do modelo devido a } \\
\text { incertezas }\end{array}$ & 0,94 & & & & \\
\hline & $\mathrm{COB}_{F}$ & Fração de COBF convertido para biogás & 0,50 & & & & \\
\hline & $\mathrm{F}$ & Fração de metano no biogás & 0,50 & & & & \\
\hline & $\mathrm{PAQ}_{\mathrm{CH} 4}$ & $\begin{array}{l}\text { Potencial de aquecimento global do } \\
\text { metano }\end{array}$ & 21 & & & & \\
\hline \multirow[t]{2}{*}{$L_{j, C B, a}=\sum_{d=1}^{365}\left(L_{j, C B, a, D P, A G}\right)_{d}+\sum_{d=1}^{365}\left(L_{j, C B, a, R A, D S, A F}\right)_{d}$} & $\mathrm{~L}_{\mathrm{T}, \mathrm{CB}, \mathrm{a}, \mathrm{DP}, \mathrm{AG}}$ & $\begin{array}{l}\text { Massa de lodo do adensador por } \\
\text { gravidade }\end{array}$ & & & & \multirow[t]{2}{*}{$\begin{array}{l}\text { Nakazato } \\
(2005)\end{array}$} & \multirow[t]{2}{*}{ (6) } \\
\hline & $\mathrm{L}_{\mathrm{I}, \mathrm{CB}, \mathrm{a}, \mathrm{RA}, \mathrm{DS}, \mathrm{AF}}$ & Massa de lodo do adensador por flotação & & & & & \\
\hline \multirow{2}{*}{$L_{j, C B, a, D P}=\sum_{d=1}^{365}\left(E \times \mathcal{Q}_{\text {bruto }} \times S S_{\text {bruto }} \times 10^{-6}\right)_{d}$} & $E(\%)$ & Eficiência do decantador primário & 63 & \multirow[t]{2}{*}{60} & \multirow[t]{2}{*}{65} & \multirow{2}{*}{$\begin{array}{l}\text { Chernicharo } \\
\quad(1997)\end{array}$} & \multirow[t]{2}{*}{ (7) } \\
\hline & $\mathrm{SS}_{\text {bruto }}(\mathrm{g} \cdot \mathrm{m}-3)$ & $\begin{array}{l}\text { Concentração de sólidos suspensos no } \\
\text { afluente }\end{array}$ & 175 & & & & \\
\hline$L_{j, C B, a, D P, A G}=C P_{A G} \times L_{J, C B, a, D P}$ & $\mathrm{cp}_{\mathrm{AG}}(\%)$ & $\begin{array}{l}\text { Capacidade de captura do adensador por } \\
\text { gravidade }\end{array}$ & 89 & 85 & 92 & $\begin{array}{l}\text { Chernicharo } \\
\text { (1997) }\end{array}$ & (8) \\
\hline \multirow[t]{4}{*}{$L_{j, C B, a, R, D S}=\sum_{d=1}^{365} L_{j, C B, R A, D S, d}$} & $\mathrm{Y}(\mathrm{g} / \mathrm{g})$ & Coeficiente de produção celular & 0,60 & 0,40 & 0,80 & \multirow[t]{4}{*}{$\begin{array}{l}\text { Chernicharo } \\
\quad(1997)\end{array}$} & \multirow[t]{4}{*}{ (9) } \\
\hline & $f_{b}$ & $\begin{array}{l}\text { Fração biodegradável dos sólidos } \\
\text { suspensos voláteis gerados no sistema }\end{array}$ & 0,53 & 0,40 & 0,65 & & \\
\hline & $\mathrm{K}_{\mathrm{d}}\left(\mathrm{d}^{-1}\right)$ & Coeficiente de respiração endógena & 0,08 & 0,06 & 0,10 & & \\
\hline & SSV/SST (\%) & $\begin{array}{l}\text { Relação entre sólidos suspensos voláteis e } \\
\text { suspensos totais no reator aerado }\end{array}$ & 78 & 70 & 85 & & \\
\hline$L_{j, C B, a, R A, D S, A F}=C P_{A F} \cdot L_{j, C B, a, R A, D S}$ & $\mathrm{Cp}_{\mathrm{AF}}(\%)$ & $\begin{array}{l}\text { Capacidade de captura do adensador por } \\
\text { flotação }\end{array}$ & 88 & 90 & 95 & $\begin{array}{l}\text { Chernicharo } \\
\text { (1997) }\end{array}$ & (10) \\
\hline \multirow{4}{*}{$\begin{aligned} E B_{e f, d e s c \arg a, a}= & \left(\mathcal{Q}_{e f, a} \times P A Q_{C H 4} \times P_{e f}\right. \\
& \times F C_{C B} \times D Q O_{e f, d e s c \arg a, C B, a} \\
& \left.\times F C M_{e f, C B, \text { desc arg } a} \times 10^{-6}\right)\end{aligned}$} & $\mathrm{Q}_{\mathrm{efta}}(\mathrm{m} 3)$ & $\begin{array}{l}\text { Volume de efluente tratado descartado no } \\
\text { corpo receptor no ano a }\end{array}$ & 16.497 .737 & & & \multirow[t]{4}{*}{$\begin{array}{l}\text { UNFCCC } \\
\text { (2009c) }\end{array}$} & \multirow[t]{4}{*}{ (11) } \\
\hline & $\begin{array}{l}\mathrm{P}_{\text {ef }}\left(\mathrm{Kg} \mathrm{CH}_{4} \cdot \mathrm{kg}\right. \\
\left.\mathrm{COD}^{-1}\right)\end{array}$ & $\begin{array}{l}\text { Capacidade de produção de metano do } \\
\text { processo de tratamento de efluente }\end{array}$ & 0,21 & & & & \\
\hline & $\mathrm{DQO}_{\text {eftddescarga, CB,a }}\left(\mathrm{g} \cdot \mathrm{m}^{-3}\right)$ & $\begin{array}{l}\text { Concentração de demanda química de } \\
\text { oxigênio residual no efluente lançado no } \\
\text { corpo receptor }\end{array}$ & 33 & & & & \\
\hline & $\mathrm{FCM}_{\mathrm{ef}, \mathrm{CB}, \mathrm{descarga}}$ & Fator de correção do metano na descarga & 0,1 & & & & \\
\hline \multirow{8}{*}{$\begin{aligned} E P_{a} & =\left(E P_{\text {energia }, a}+E P_{e f, \text { tratamento }, a}\right. \\
& +E P_{l, \text { tratameneto }, a}+E P_{e f, \text { descarg } a, a} \\
& +E P_{l, \text { disposiçá, }, a}+E P_{\text {liberado }, a} \\
& \left.+E P_{\text {biomassa }, a}+E P_{\text {queima }, a}\right)\end{aligned}$} & $\mathrm{EP}_{\text {energia,a }}\left(\mathrm{tCO}_{2} \mathrm{e}\right)$ & \multicolumn{4}{|c|}{$\begin{array}{l}\text { Emissões da quantidade consumida de eletricidade ou diesel no ano } \\
\text { a, no caso será nulo, uma vez que a fonte de energia é de baixo custo } \\
\text { (UNFCCC, 2009d) }\end{array}$} & \multirow[t]{8}{*}{$\begin{array}{l}\text { UNFCCC } \\
(2009 \mathrm{c})\end{array}$} & \multirow[t]{8}{*}{ (12) } \\
\hline & $\mathrm{EP}_{\text {eftrtatamento } \mathrm{a}}\left(\mathrm{tCO}_{2} \mathrm{e}\right)$ & \multicolumn{4}{|c|}{$\begin{array}{l}\text { Emissões do sistema de tratamento de efluentes pós-projeto MDL e } \\
\text { sem recuperação de biogás - no caso, será nula (sistema aeróbio bem } \\
\text { operado) }\end{array}$} & & \\
\hline & $\mathrm{EP}_{1, \text { tratamento,a }}\left(\mathrm{tCO}_{2} \mathrm{e}\right)$ & \multicolumn{4}{|c|}{$\begin{array}{l}\text { Emissões do tratamento do lodo afetado pós-projeto MDL e sem } \\
\text { recuperação de biogás - no caso será nula (projeto prevê a queima do } \\
\text { biogás) }\end{array}$} & & \\
\hline & $\mathrm{EP}_{\text {ef,descarga,a }}\left(\mathrm{tCO}_{2} \mathrm{e}\right)$ & \multicolumn{4}{|c|}{ Emissões da matéria orgânica residual do efluente tratado no ano a } & & \\
\hline & $\mathrm{EP}_{1, \text { disposiçâa,a }}\left(\mathrm{tCO}_{2} \mathrm{e}\right)$ & \multicolumn{4}{|c|}{$\begin{array}{l}\text { Emissões da matéria orgânica do lodo - no caso, será nula (lodo } \\
\text { utilizado como condicionador do solo) }\end{array}$} & & \\
\hline & $\mathrm{EP}_{\text {liberado,a }}\left(\mathrm{tCO}_{2} \mathrm{e}\right)$ & \multicolumn{4}{|c|}{ Emissões de metano liberado no sistema de captura } & & \\
\hline & $\mathrm{EP}_{\text {biomassa,a }}\left(\mathrm{tCO}_{2} \mathrm{e}\right)$ & \multicolumn{4}{|c|}{$\begin{array}{l}\text { Emissões da biomassa estocada em condições anaeróbias - no caso, } \\
\text { será nula (também presente no cenário de linha de base) }\end{array}$} & & \\
\hline & $\mathrm{EP}_{\text {queima,a }}\left(\mathrm{tCO}_{2} \mathrm{e}\right)$ & \multicolumn{4}{|l|}{ Emissão devido à queima incompleta do biogás } & & \\
\hline
\end{tabular}

*Equação obtida a partir do ajuste de um modelo empírico aos dados encontrados por diversos autores e apresentados por Jordão e Pessôa (2005) (ajuste satisfatório, $\left.\mathrm{R}^{2}=0,829\right)$ Co: constante; Li: limite inferior; Ls: limite superior. 
Tabela 1 - Descrição dos modelos matemáticos utilizados na modelagem (continuação)

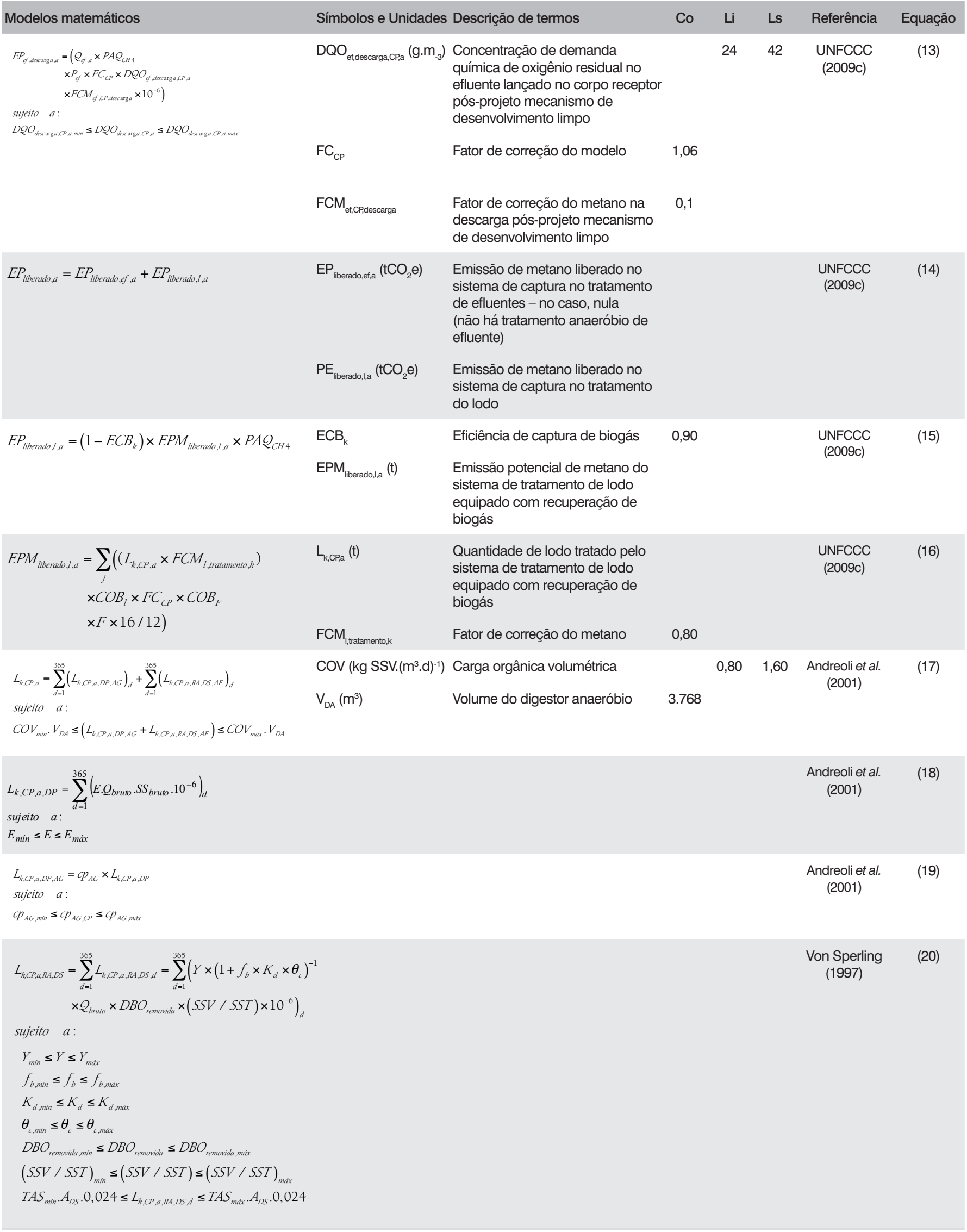

*Equação obtida a partir do ajuste de um modelo empírico aos dados encontrados por diversos autores e apresentados por Jordão e Pessôa (2005) (ajuste satisfatório, $\left.\mathrm{R}^{2}=0,829\right)$ Co: constante; Li: limite inferior; Ls: limite superior. 
Tabela 1 - Descrição dos modelos matemáticos utilizados na modelagem (continuação).

\begin{tabular}{|c|c|c|c|c|c|c|c|}
\hline Modelos matemáticos & Símbolos e Unidades & Descrição de termos & Co & $\mathrm{Li}$ & Ls & Referência & Equação \\
\hline $\begin{array}{l}L_{k, C P, a, R A, D S, A F}=C P_{A F} \times L_{k, C P, a, R A, D S} \\
\text { sujeito } a: \\
c P_{A F, \text { min }} \leq c P_{A F} \leq C P_{A F, \text { max }}\end{array}$ & & & & & & $\begin{array}{l}\text { Von Sperling } \\
\quad(1997)\end{array}$ & (21) \\
\hline$Y=0,3126 \times \operatorname{Ln}\left(K_{d}\right)+1,4672$ * & & & & & & Autores & (22) \\
\hline$f_{b}=0,8 \times\left(1+0,2 \times K_{d} \times \theta_{c}\right)^{-1}$ & & & & & & $\begin{array}{l}\text { Von Sperling } \\
\text { (1997) }\end{array}$ & (23) \\
\hline$T A S=Q_{\text {bruto }} \times(R+1) \times S S T \times A_{D S}^{-1} \times 2,4.10^{-4}$ & $\begin{array}{l}\text { TAS }\left(\mathrm{kg} \cdot\left(\mathrm{m}^{2} \cdot \mathrm{h}\right)^{-1}\right) \\
\mathrm{A}_{\mathrm{DS}}\left(\mathrm{m}^{2}\right)\end{array}$ & $\begin{array}{l}\text { Taxa de aplicação de sólidos } \\
\text { Área do decantador secundário }\end{array}$ & 803 & 4 & 10 & $\begin{array}{l}\text { Von Sperling } \\
\quad(1997)\end{array}$ & (24) \\
\hline$E P_{\text {queima }, a}=\sum_{h=1}^{8760} T M_{G R, h} \times\left(1-\eta_{\text {queima }, h}\right) \times P A Q_{C H 4} \times 10^{-3}$ & $\begin{array}{l}\mathrm{TM}_{\mathrm{GR}, \mathrm{h}}\left(\mathrm{kg} \cdot \mathrm{h}^{-1}\right) \\
\eta_{\text {queima,h }}(\%)\end{array}$ & $\begin{array}{l}\text { Taxa de fluxo de massa do } \mathrm{CH}_{4} \text { do gás } \\
\text { Eficiência de queima }\end{array}$ & 50 & & & $\begin{array}{l}\text { UNFCCC } \\
\text { (2009e) }\end{array}$ & (25) \\
\hline$T M_{G R, h}=F V_{G R, h} \cdot f v_{C H 4, G R, h} \cdot \rho_{C H 4, n}$ & $\begin{array}{l}\mathrm{FV}_{\mathrm{GR}, \mathrm{h}}\left(\mathrm{m}^{3} \cdot \mathrm{h}^{-1}\right) \\
\mathrm{fV}_{\mathrm{CH} 4, \mathrm{GR}, \mathrm{h}} \\
\rho_{\mathrm{CH} 4, \mathrm{n}}\left(\mathrm{kg} \cdot \mathrm{m}^{-3}\right)\end{array}$ & $\begin{array}{l}\text { Vazão do gás residual em base seca } \\
\text { Fração volumétrica do } \mathrm{CH}_{4} \\
\text { Densidade do metano }\end{array}$ & $\begin{array}{l}0,50 \\
0,72\end{array}$ & & & $\begin{array}{l}\text { UNFCCC } \\
(2009 e)\end{array}$ & (26) \\
\hline $\begin{array}{l}F V_{G R, h}=P_{\text {biogas }, D A} \times L_{k, C P, a} \times E_{S S V, D A} \times 0,114 \\
\text { sujeito } \quad a: \\
E_{S S V, D A, \min } \leq E_{S S V, D A} \leq E_{S S V, D A, \max }\end{array}$ & $\begin{array}{l}P_{\text {biogas,DA }}\left(m^{3} \text { biogás }\right. \\
\left.\text { kg SSV }^{-1}\right) \\
E_{\text {SSV,DA }}(\%)\end{array}$ & $\begin{array}{l}\text { Produção estimada de biogás no } \\
\text { reator anaeróbio } \\
\text { Eficiência na redução de sólidos } \\
\text { voláteis do digestor anaeróbio }\end{array}$ & 0,80 & 40 & 55 & $\begin{array}{l}\text { UNFCCC } \\
(2009 \mathrm{e})\end{array}$ & (27) \\
\hline
\end{tabular}

*Equação obtida a partir do ajuste de um modelo empírico aos dados encontrados por diversos autores e apresentados por Jordão e Pessôa (2005) (ajuste satisfatório, R²=0,829) Co: constante; Li: limite inferior; Ls: limite superior.

\section{Etapa 4: Modelagem de otimização e extração de parâmetros ótimos operacionais}

Apoiando-se na modelagem matemática do sistema, foi possível otimizar a redução das emissões de carbono na ETEB-Norte, que podem ser direta ou indiretamente relacionadas às variáveis apresentadas. O modelo de otimização parte da hipótese de que é possível existir uma ETE que opera em condições ótimas de redução de emissões de GEE. Dessa forma, foi proposta uma função objetivo descrevendo a maximização das reduções de emissões. A fim de alcançar os objetivos descritos, empregou-se um software para otimização, acessível e de fácil utilização, denominado ExcelSolver, desenvolvido pela Microsoft Inc. e fundamentado em técnica de otimização não linear do Gradiente Reduzido Generalizado (GRG2). Essa técnica é baseada em uma movimentação iterativa de um ponto " $x$ " qualquer, até que seja atingido um ponto " $\mathrm{x}+\mathrm{Dx}$ ", que otimiza a função objetivo e satisfaz as restrições do problema (ROSAL, 2007). Mais informações sobre processos internos de resolução do software de otimização Excel-Solver podem ser obtidas no site http://www.solver.com/.

\section{Resultados}

A seguir estão apresentados os resultados obtidos das etapas propostas na metodologia (Etapas de 1 a 4). Em relação à Etapa 1, podem-se mencionar como possíveis alternativas para a captura do metano as seguintes: substituição do sistema de tratamento aeróbio de efluente ou lodo por sistema anaeróbio com captura e queima de metano; e introdução de sistema de captura e queima de metano. Têm-se, ainda, alternativas de aproveitamento do metano capturado diferentes da queima, podendo ser aplicadas como soluções a geração direta de energia elétrica, a geração de energia elétrica após tratamento e armazenamento do biogás, e a produção de hidrogênio. A proposição das alternativas seguiu o sugerido pela UNFCCC (2009c), para a implantação de projetos MDL em ETE, assim, todas as alternativas propostas são passíveis de certificação e podem atender os aspectos de elegibilidade de projetos MDL.

O conhecimento do fluxograma do sistema adotado na ETEBNorte, como mostrado na Figura 2, aliado ao das possíveis alternativas à implantação de projetos MDL (Etapa 1), permitiu o desenvolvimento da Etapa 2. Uma série de opções e combinações puderam ser elaboradas, mas, como foi proposta no trabalho a implantação de projeto MDL com mínimas modificações na planta, adotou-se como cenário para o desenvolvimento dos estudos a alternativa de introdução de sistema composto pela captura e queima do metano produzido no digestor anaeróbio.

De posse das características da ETEB-Norte, apresentadas na Tabela 2, e da alternativa a ser proposta, iniciou-se a Etapa 3.

São apresentados na Tabela 1 os modelos matemáticos referentes às variáveis operacionais da ETEB-Norte, a descrição do cenário de linha de base (representa as emissões de GEE nas condições atuais, ou seja, na ausência do projeto MDL), as emissões das atividades do projeto MDL e as reduções de emissões do projeto MDL. 


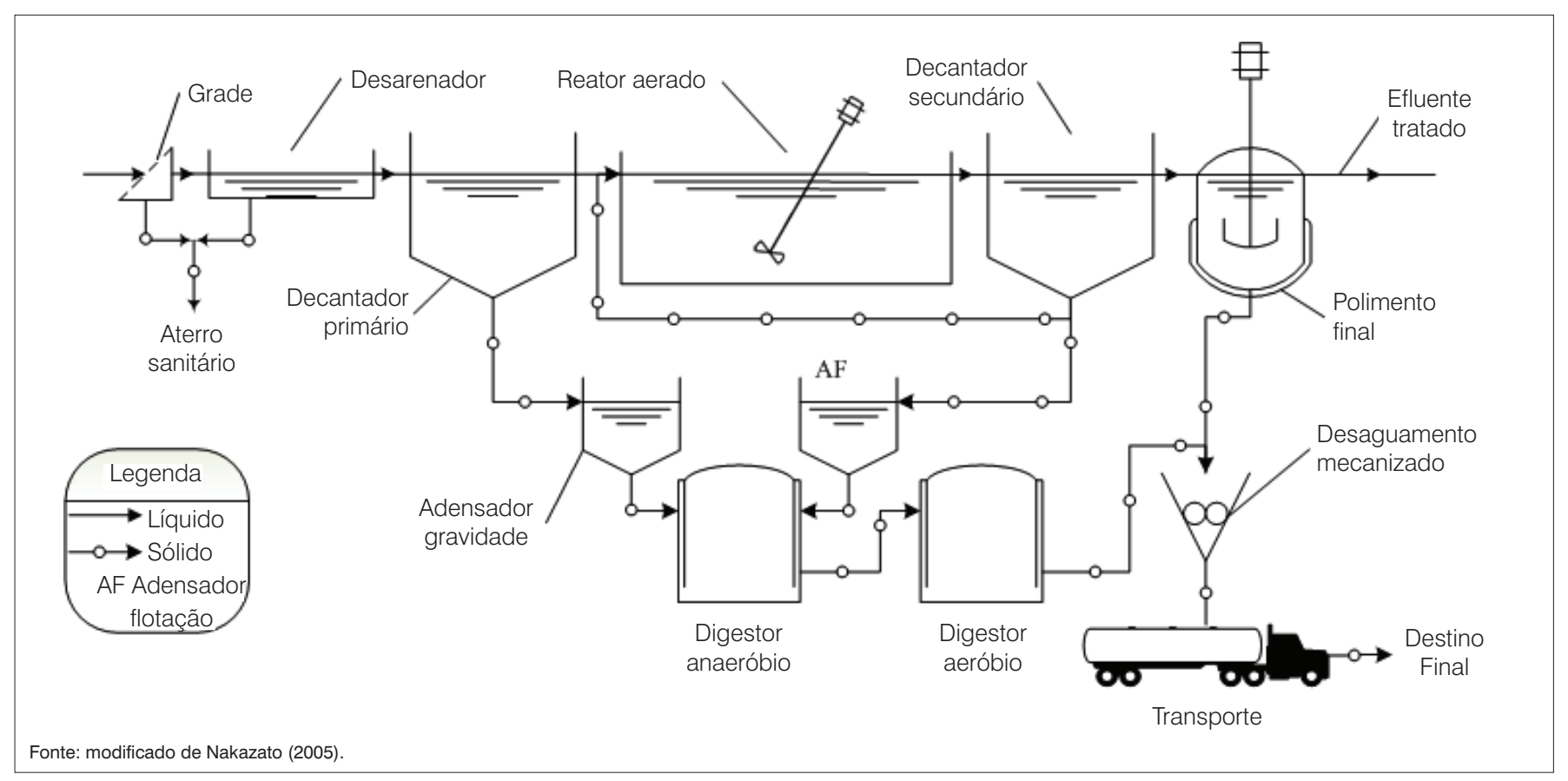

Figura 2 - Fluxograma do sistema de tratamento de lodos ativados a nível terciário da Estação de Tratamento de Esgoto Brasília Norte.

Segundo Metcalf \& Eddy (2002), as principais variáveis operacionais nos sistemas de lodos ativados, caso do sistema de tratamento de efluentes estudado, são o nível de aeração, a vazão de recirculação e a vazão do lodo excedente. O nível de aeração pode ser estimado por meio do pico de demanda por oxigênio $\left(R O_{d}\right)$, calculado conforme a Equação 1. A vazão de recirculação $\left(Q_{\mathrm{re}}\right)$ e a vazão do lodo excedente $\left(Q_{\mathrm{ex}}\right)$ são as variáveis de manipulação que controlam a massa total de sólidos no sistema de lodos ativados, dadas pelas Equações 2 e 3 .

Os modelos matemáticos adotados para representar o cenário de linha de base $\left(E B_{a}\right)$, as emissões das atividades do projeto MDL $\left(E P_{a}\right)$ e as reduções de emissões do projeto MDL $\left(R E_{a}\right)$ foram fundamentados na metodologia proposta pelo UNFCCC para seleção de projetos MDL em pequena escala. $O E B_{a}$ é dado pela Equação 4 (UNFCCC, 2009c) e os valores das variáveis operacionais envolvidas foram obtidos a partir de dados operacionais da ETEB-Norte, apresentados nas Tabelas 1 e 2. Para a realização do cálculo completo do $E B_{a}$, fez-se necessária a utilização de uma série de modelos matemáticos complementares, os quais estão apresentados nas Equações 5 até 11 . A Figura 3 apresenta um diagrama relacionando equações e variáveis de entrada para o modelo $E B_{a}$.

Considerando o cálculo das emissões das atividades de projeto $\left(E P_{\mathrm{a}}\right)$, dado pela Equação 12 (UNFCCC, 2009c), e a hipótese da existência de condições operacionais que maximizam as reduções de emissões de GEE, foram inseridas restrições para as variáveis operacionais envolvidas. Da mesma forma que para a realização do cálculo do $E B_{a}$, no cálculo de $E P_{a}$ utilizou-se uma série de modelos matemáticos complementares, representados nas Equações 13
Tabela 2 - Desempenho operacional da Estação de Tratamento de Esgoto Brasília Norte (ano de referência: 2008).

\begin{tabular}{|c|c|c|}
\hline Dados & Afluente / Efluente / Remoção & Média anual \\
\hline \multirow[t]{3}{*}{ Vazão $\left(m^{3}\right)$} & Afluente & $1.267 .645,0$ \\
\hline & Efluente & $1.267 .645,0$ \\
\hline & Vazão tratada / vazão de projeto (\%) & 52,3 \\
\hline \multirow{3}{*}{$\begin{array}{l}\text { Demanda } \\
\text { bioquímica de } \\
\left.\text { oxigênio (mg. } \mathrm{L}^{-1}\right)\end{array}$} & Afluente & 296,0 \\
\hline & Efluente & 8,4 \\
\hline & Remoção (\%) & 97,2 \\
\hline \multirow{3}{*}{$\begin{array}{l}\text { Demanda química } \\
\text { de oxigênio (mg. } \mathrm{L}^{-1} \text { ) }\end{array}$} & Afluente & 468,0 \\
\hline & Efluente & 45,4 \\
\hline & Remoção (\%) & 90,2 \\
\hline \multirow{3}{*}{$\begin{array}{l}\text { Nitrogênio total de } \\
\left.\text { Kjeldahl (mg. } \mathrm{L}^{-1}\right)\end{array}$} & Afluente & 45,5 \\
\hline & Efluente & 7,5 \\
\hline & Remoção (\%) & 89,2 \\
\hline \multirow{3}{*}{$\begin{array}{l}\text { Fósforo total } \\
\left(\mathrm{mg} \cdot \mathrm{L}^{-1}\right)\end{array}$} & Afluente & 6,6 \\
\hline & Efluente & 0,3 \\
\hline & Remoção (\%) & 95,2 \\
\hline \multirow{3}{*}{$\begin{array}{l}\text { Sólidos suspensos } \\
\left(\mathrm{mg} \cdot \mathrm{L}^{-1}\right)\end{array}$} & Afluente & 210,0 \\
\hline & Efluente & 9,1 \\
\hline & Remoção (\%) & 95,6 \\
\hline \multirow{3}{*}{$\begin{array}{l}\text { Coliformes } \\
\text { termotolerantes }\end{array}$} & Afluente & $6,0 \mathrm{E}+07$ \\
\hline & Efluente & $1,7 \mathrm{E}+05$ \\
\hline & Remoção (\%) & 99,4 \\
\hline $\begin{array}{l}\text { Demanda por } \\
\text { oxigênio }\left(R O_{d}\right)^{*}\end{array}$ & $\mathrm{~kg} \mathrm{O}_{2} \cdot \mathrm{d}^{-1}$ & $14.736,0$ \\
\hline $\begin{array}{l}\text { Vazão de lodo } \\
\text { excedente }\left(Q_{e x}\right)^{\star}\end{array}$ & $m^{3} \cdot d^{-1}$ & $1.887,0$ \\
\hline $\begin{array}{l}\text { Vazão de } \\
\text { recirculação }\left(Q_{\mathrm{re}}\right)^{\text {* }}\end{array}$ & $m^{3} \cdot d^{-1}$ & $68.036,0$ \\
\hline
\end{tabular}

*Valores estimados a partir de dados disponibilizados pela Companhia de Saneamento Ambiental do Distrito Federal Fonte: CAESB (2009). 


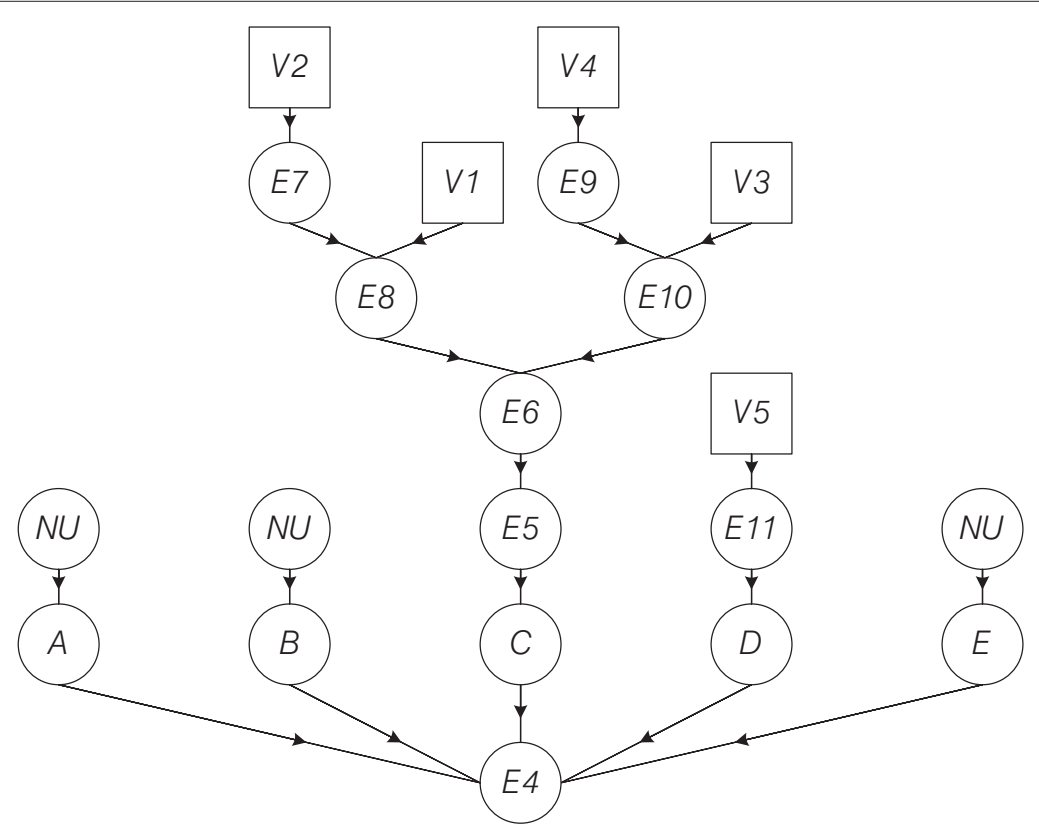

E4, E5, ..., E11: Equações 4, 5, ..., 11, apresentadas na Tabela 1; A: termo emissões da quantidade consumida de eletricidade ou diesel no ano a; B: termo emissões do sistema de tratamento de efluentes no ano a; C: termo emissões do tratamento do lodo no ano a; D: termo emissões da matéria orgânica residual do efluente tratado no ano a; E: termo emissões da matéria orgânica residual do lodo no ano a; NU: valor nulo adotado para os termos, sendo as justificativas para a nulidade apresentadas na Tabela 1; V1, V2, ..., V5: conjuntos de variáveis de entrada das equações indicadas, segundo o apresentado nesta Figura e na Tabela 1 (por exemplo, o conjunto de variáveis V1, que alimenta a Equação 8 , é composto por uma única variável: a capacidade de captura do adensador por gravidade).

Figura 3 - Diagrama relacionando equações e variáveis de entrada para o modelo $E B_{\text {a. }}$
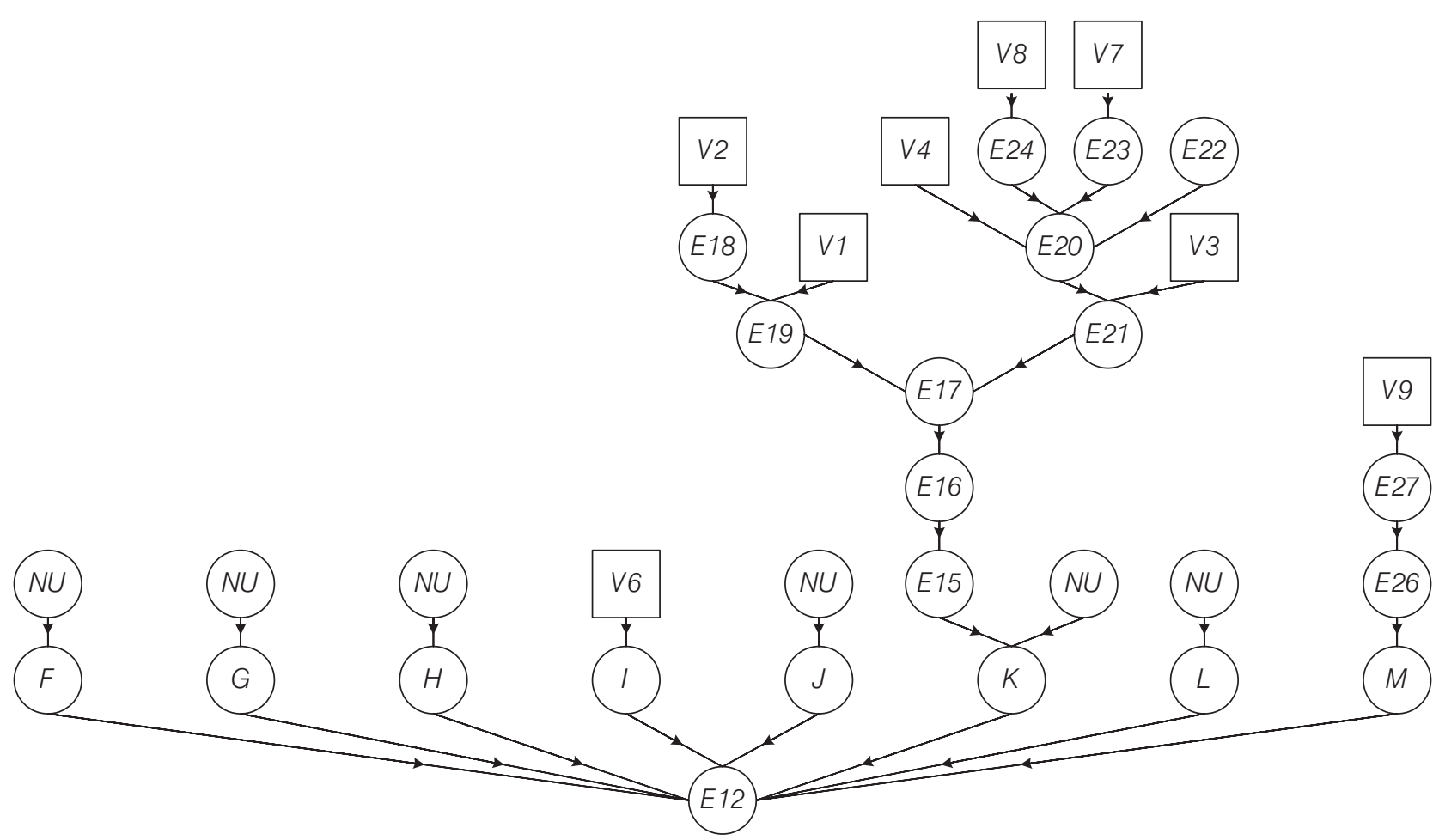

E12, E13, .... E27: Equações 12, 13, ..., 27, apresentadas na Tabela 1; F: termo emissões da quantidade consumida de eletricidade ou diesel no ano a; G: termo emissões do sistema de tratamento de efluentes pós-projeto MDL e sem recuperação de biogás; H: termo emissões do tratamento do lodo afetado pós-projeto MDL e sem recuperação de biogás; l: termo emissões da matéria orgânica residual do efluente tratado no ano a; J: termo emissões da matéria orgânica do lodo; K: termo emissões de metano liberado no sistema de captura; L: termo emissões da biomassa estocada em condições anaeróbias; M: termo emissão devido à queima incompleta do biogás; NU: valor nulo adotado para os termos, sendo as justificativas para a nulidade apresentadas na Tabela 1; V1, V2, ..., V9: conjuntos de variáveis de entrada das equações indicadas, segundo o apresentado nesta Figura e na Tabela 1 (por exemplo, o conjunto de variáveis V2, que alimenta a Equação 18, é composto pelas variáveis eficiência do decantador primário, vazão média do afluente bruto e concentração de SS no afluente).

Figura 4 - Diagrama relacionando equações e variáveis de entrada para o modelo $E P_{\mathrm{a}}$. 
a 27. A Figura 4 apresenta um diagrama relacionando equações e variáveis de entrada para o modelo $E P_{\text {a }}$. Os valores das constantes e restrições envolvidas foram obtidos a partir da pesquisa bibliográfica e dos dados cedidos pela Companhia de Saneamento Ambiental do Distrito Federal (CAESB). Menciona-se, ainda, que as emissões geradas a partir do condicionamento aeróbio de lodo foram consideradas nulas, seguindo as recomendações do UNFCCC (2009c) para os casos em que o lodo é utilizado como um agente de correção de solos.

Considerando que as equações utilizadas para modelagem do problema referem-se a um conjunto de modelos já reconhecidos e tradicionalmente recomendados para o dimensionamento de ETE, e também o fato da impossibilidade de validação do modelo, do ponto de vista prático (o que exigiria a realização de uma importante quantidade de medições de emissões de carbono da ETEB-Norte, a variabilidade nos valores de entrada do modelo e a verificação de valores observados e estimados pelo modelo), assumiu-se que o modelo proposto é validado.

A etapa seguinte (Etapa 4) refere-se à formulação do modelo de otimização e extração do ponto ótimo operacional, fundamentado nos modelos matemáticos já mencionados. Foi utilizada uma função objetivo para descrever a maximização da redução de emissões de carbono $\left(R E_{\mathrm{a}}\right)$ para o projeto MDL proposto, que está expressa pela Equação 28 (UNFCCC, 2009c). As restrições do modelo de otimização que se referem ao atendimento à legislação e às características operacionais da ETEB-Norte são apresentadas nas Tabelas 1 e 2. Outra restrição considerada refere-se à necessidade dos valores de $E P_{\text {a }}$ serem menores ou iguais ao $E B_{a}$, o que garante o aspecto da adicionalidade do projeto MDL. Também, com a finalidade de verificar a influência dos pontos extremos de tratamento de efluentes no $R E_{a}$, foram analisados quatro diferentes, considerando: (i) máximo da remoção de $\mathrm{DBO}$; (ii) mínimo da remoção de $\mathrm{DBO}$; (iii) máximo da quantidade de lodo encaminhado ao digestor anaeróbio; e (iv) mínimo da quantidade de lodo encaminhado ao digestor anaeróbio. Os cenários diretamente relacionados a variações nas condições de operacionais da ETEB-Norte, ou seja, alterações de eficiências e parâmetros operacionais. As Equações 29, 30, 31 e 32 representam os cenários (i), (ii), (iii) e (iv), respectivamente.

máx $R E_{a}=E B_{a}-E P_{a}$

sujeito a:

$E P_{a} \leq E B_{a}$

máx $D B O_{\text {removida }}=D B O_{\text {bruto }}-D B O_{\text {descarg } a, C P, a}$

sujeito a

$E P_{a} \leq E B_{a}$

min $D B O_{\text {removida }}=D B O_{\text {bruto }}-D B O_{\text {desc arg } a, C P, a}$

sujeito $a$ :

$E P_{a} \leq E B_{a}$

máx $L_{k, C P, a}=\sum_{d=1}^{365}\left(L_{k, C P, a, D P, A G}\right)_{d}+\sum_{d=1}^{365}\left(L_{k, C P, a, R A, D S, A F}\right)$

sujeito a

$E P_{a} \leq E B_{a}$

$\min L_{k, C P, a}=\sum_{d=1}^{365}\left(L_{k, C P, a, D P, A G}\right)_{d}+\sum_{d=1}^{365}\left(L_{k, C P, a, R A, D S, A F}\right)_{d}$

sujeito $a$ :

$E P_{a} \leq E B_{a}$

Tabela 3 - Valores de reduções de emissões do projeto $\operatorname{MDL}\left(R E_{\mathrm{a}}\right)$, cenário de linha de base $\left(E B_{z}\right)$, emissões das atividades do projeto $M D L\left(E P_{2}\right)$ e ótimos operacionais para os respectivos cenários.

\begin{tabular}{|c|c|c|c|c|c|c|}
\hline Variáveis & Unidades & máx. $R E_{\mathrm{a}}(\mathrm{A})$ & Cenário 1 (B) & Cenário 2 (C) & Cenário 3 (D) & Cenário 4 (E) \\
\hline$R E_{\mathrm{a}}$ & $\mathrm{tCO}_{2} \mathrm{e}$ & $6.184,6$ & $6.169,6$ & $6.184,6$ & $6.133,0$ & $6.184,6$ \\
\hline$E B_{\mathrm{a}}$ & $\mathrm{tCO}_{2} \mathrm{e}$ & $7.037,9$ & $7.037,9$ & $7.037,9$ & $7.037,9$ & $7.037,9$ \\
\hline$E P_{\mathrm{a}}$ & $\mathrm{tCO}_{2} \mathrm{e}$ & 853,3 & 868,3 & 853,3 & 904,9 & 853,3 \\
\hline$D Q O_{\text {descarga,a }}$ & $\mathrm{g} \cdot \mathrm{m}^{-3}$ & 24 & 25 & 24 & 27 & 24 \\
\hline$L_{\mathrm{k}, \mathrm{CP}, \mathrm{a}}$ & $\mathrm{t}$ & $3.014,4$ & $3.016,3$ & $3.014,4$ & $3.115,4$ & $3.014,4$ \\
\hline$E$ & $\%$ & 63 & 61 & 62 & 65 & 61 \\
\hline$c p_{\mathrm{AG}}$ & $\%$ & 90 & 86 & 86 & 89 & 86 \\
\hline$\theta_{c}$ & $d$ & 5,7 & 4,6 & 4,0 & 5,2 & 4,0 \\
\hline$D B O_{\text {removida,a }}$ & $\mathrm{g} \cdot \mathrm{m}^{-3}$ & 274 & 294 & 273 & 282 & 275 \\
\hline SSV/SST & $\%$ & 76 & 72 & 71 & 76 & 71 \\
\hline TAS & $\mathrm{kg} \cdot\left(\mathrm{m}^{2} \cdot \mathrm{h}\right)^{-1}$ & 9,98 & 10,00 & 8,59 & 10,00 & 8,65 \\
\hline$R$ & $\%$ & 70 & 75 & 70 & 79 & 70 \\
\hline$c p_{\mathrm{AF}}$ & $\%$ & 86 & 82 & 81 & 86 & 81 \\
\hline COV & kg SSV. $\left(m^{3} \cdot d\right)^{-1}$ & 0,80 & 0,80 & 0,80 & 0,83 & 0,80 \\
\hline$R O$ & $\mathrm{~kg} \mathrm{O}_{2} \cdot \mathrm{d}^{-1}$ & $11.883,8$ & $12.330,4$ & $10.926,2$ & $12.136,3$ & $10.996,7$ \\
\hline$Q_{e x}$ & $m^{3} \cdot d^{-1}$ & $2.311,3$ & $2.872,9$ & $3.303,8$ & $2.543,5$ & $3.303,8$ \\
\hline$Q_{\mathrm{re}}$ & $m^{3} \cdot d^{-1}$ & $31.750,4$ & $34.018,2$ & $31.750,4$ & $35.702,9$ & $31.750,4$ \\
\hline
\end{tabular}

Os resultados foram obtidos considerando a introdução de sistema de captura e queima do metano produzido no digestor anaeróbio.

A, B, C, D e E são os resultados da otimização das funções objetivos e restrições, apresentadas nas equações $28,29,30,31$ e 32, respectivamente. 
(a)

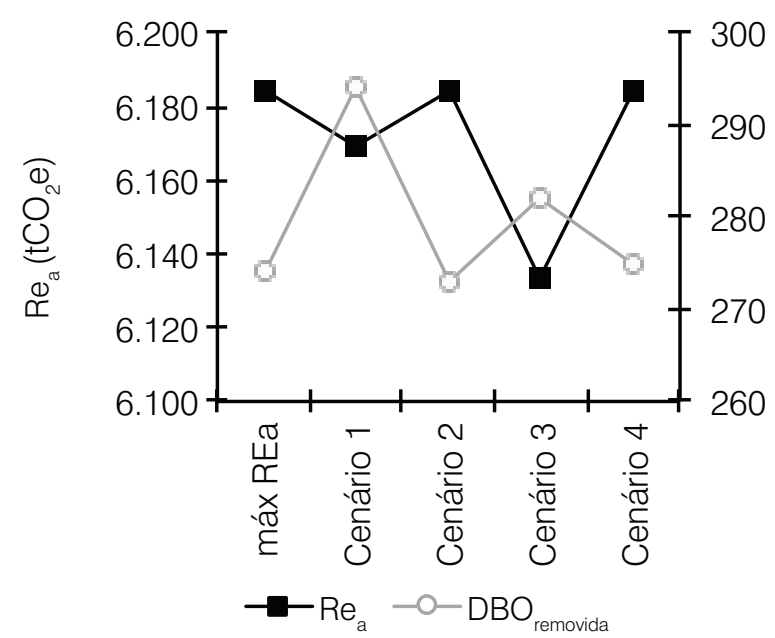

Figura 5 - (a) $R E_{a}$ versus $D B O_{\text {removida; }}$ (b) $R E_{\mathrm{a}}$ versus $L_{\mathrm{k}, \mathrm{CP}, \mathrm{a}}$.

A otimização das equações 28 a 32, sujeito a todas as restrições do problema (modelagem matemática da ETEB-Norte; restrições apresentadas na Tabela 1; introdução de sistema de captura e queima do metano no digestor anaeróbio) resultou nos valores de redução de emissões de GEE e nos ótimos operacionais apresentados na Tabela 3. O cenário de linha de base $\left(E B_{\mathrm{a}}\right)$ indicou um valor de $7038 \mathrm{tCO}_{2} \mathrm{e}$ por ano (Tabela 3). Como ótimo operacional da ETEB-Norte, quando se maximiza a redução das emissões de GEE (máx $R E$ ), obtiveram-se valores de demanda requerida de oxigênio de $R O=11.884 \mathrm{kgO}_{2} \cdot \mathrm{d}^{-1}$, vazão de descarte de lodo de $Q_{\mathrm{ex}}=2.311 \mathrm{~m}^{3} \cdot \mathrm{d}^{-1}$ e vazão de recirculação de lodo de $Q_{\mathrm{re}}=31.750 \mathrm{~m}^{3}$. $\mathrm{d}^{-1}$, sendo possível atingir reduções de emissões de GEE de $R E_{\mathrm{a}}=6.185 \mathrm{tCO}_{2}$ e por ano. Observaram-se, ainda, valores de idade do lodo de $\theta_{c}=5,7 \mathrm{~d}$, relação de SSVISST de $76 \%$, e razão de recirculação de $R=70 \%$, o que induz à ideia de que os sistemas de lodos ativados que operam com lodo relativamente jovem e com altas concentrações no lodo de retorno tendem a apresentar maiores valores de reduções de emissões de GEE.

Outro ponto refere-se à observação de que os cenários de minimização da eficiência do tratamento (cenários 2 e 4) tendem a apresentar maiores valores de reduções de emissões de GEE, conforme mostram as Figuras $5 \mathrm{a}$ e $5 \mathrm{~b}$. Como justificativa para essa observação, recorreu-se à formulação matemática do problema, em que fatores como a redução da quantidade de lodo tratado pelo sistema de tratamento de lodo (relacionados às variáveis como eficiência do decantador primário, capacidade de captura do adensador por gravidade, e DBO removida) minimizam as emissões das atividades do projeto MDL e maximizam a reduções de emissões de GEE. (b)

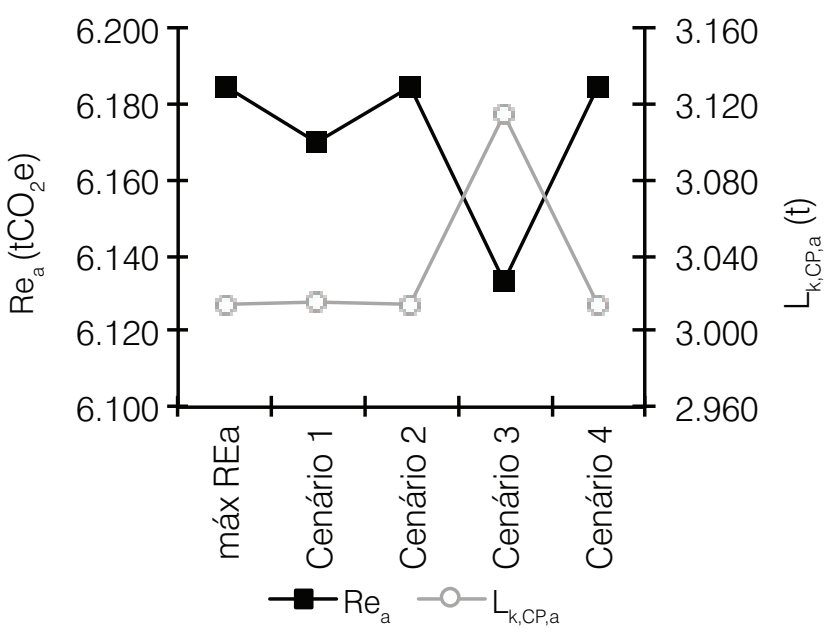

Assim, a redução na eficiência no tratamento implicará na também redução da emissão de $\mathrm{CO}_{2}$ apenas na ETE. Como a matéria orgânica não foi completamente exaurida na ETE, as emissões devidas à degradação da matéria orgânica remanescente poderão ocorrer no corpo receptor, caso não seja respeitado o equilíbrio natural entre os processos de respiração e fotossíntese. Este resultado levanta uma discussão: a metodologia de certificação de redução de emissões de carbono é uma ferramenta de incentivo à preservação e conservação ambiental, ou é meramente uma ferramenta empresarial de marketing? Especificamente para o estudo de caso da ETEB-Norte, nota-se que minimizar emissões de GEE significa diminuir o grau de tratamento das águas residuárias e, portanto, aumentar a quantidade de matéria orgânica não degradada na ETE, que é lançada no meio ambiente, com potencial de maiores emissões de GEE no corpo receptor, caso o gás carbônico produzido no ambiente aquático não seja totalmente utilizado pela comunidade fotossintetizante. Além disso, deve-se considerar, também, que ao se diminuir o grau de tratamento das águas residuárias há aumento na possibilidade de danos ao ecossistema aquático e aos usuários da água.

Observa-se, então, contradição entre a proposta de sustentabilidade representada pelo projeto MDL e a prática no sistema de tratamento de águas residuárias. Essa contradição sugere a necessidade de discussões para que se possa alcançar o real objetivo da sustentabilidade ambiental, que deveria ser contido na proposta dos projetos MDL. 


\section{Conclusões}

As alternativas para a implementação de um projeto MDL com mínima modificação e otimização operacional de uma ETE foram determinadas e o processo de seleção dessas alternativas foi apresentado no presente trabalho. Elas referem-se à introdução de sistema de captura e queima do metano no digestor anaeróbio. Para o valor ótimo operacional, especificamente da ETE Brasília Norte, foram obtidos os valores de requisito de oxigênio de $495 \mathrm{~kg}$. $\mathrm{h}^{-1}$, vazão excedente de $96,3 \mathrm{~m}^{3} \cdot \mathrm{h}^{-1}$, vazão de recirculação de $1.322,9 \mathrm{~m}^{3} \cdot \mathrm{h}^{-1}$, idade do lodo de 5,7 d, relação de SSVISST de $76 \%$ e razão de recirculação de 70\%. O estudo de cenários de máximo e mínimo de eficiência do tratamento de efluentes indicou contradição entre a proposta de incentivo para sustentabilidade dos projetos MDL e a qualidade do efluente tratado. Como consequência, o resultado obtido para o estudo de caso leva à conclusão de que mais pesquisas e discussões são necessárias para a adequação da metodologia de cálculo e certificação de projetos MDL em estações de tratamento de águas residuárias.

\section{Agradecimentos}

Os autores agradecem ao Conselho Nacional de Desenvolvimento Científico e Tecnológico (CNPq) e à Coordenação de Aperfeiçoamento de Pessoal de Nível Superior (CAPES), pelo auxílio financeiro, e à Companhia de Saneamento Ambiental do Distrito Federal (CAESB), pelo fornecimento de dados para o desenvolvimento do trabalho.

\section{Referências}

ANDREOLI, C.V.; VON SPERLING, M.; FERNANDES, F. (2001) Lodo de esgotos: tratamento e disposição final. Belo Horizonte: Departamento de Engenharia Sanitária e Ambiental - UFMG. 484 p.

CAESB - COMPANHIA DE SANEAMENTO AMBIENTAL DO DISTRITO FEDERAL. Água e esgotos no Distrito Federal: Sistemas de esgoto. Disponível em: <http://www.caesb.df.gov.br/_conteudo/ produtosServicos/sistemasEsgotos.asp\# > . Acesso em: 16 jan. 2009.

CARBONO BRASIL. Biblioteca. Disponível em: <http://www. institutocarbonobrasil.org.br/biblioteca> . Acesso em: 8 mai. 2011.

CHERNICHARO, C.A.L. (1997) Reatores anaeróbios. Belo Horizonte: SEGRAC. $246 \mathrm{p}$.

EL-FADEL, M.; MASSOUD, M. (2001) Methane emissions from wastewater management. Environmental Pollution, v. 114, n. 2, p. 177-85.

JORDÃO, E.P.; PESSOA, C.A. (2005) Tratamento de esgotos domésticos. 4 ed. Rio de Janeiro: ABES. 681 p.

KOUTSOYIANNIS, D.; EFSTRATIADIS, A.; MAMASSIS, N.; CHRISTOFIDES, A. (2008) On the credibility of climate predictions. Hydrological Sciences Journal, v. 53, n. 4, p. 671-84.

LIBORIO, I.T. (2005) Bases do mecanismo de desenvolvimento limpo. 41 f. Monografia (graduação em Ciências Jurídicas e Sociais) Universidade de Federal do Rio de Janeiro, Angra dos Reis.

MCTI. Ministério da Ciência, Tecnologia e Inovação - Programa Nacional de Mudanças Climáticas - Mecanismo de Desenvolvimento Limpo (MDL). Disponível em: < http://www.mct.gov.br/index.php/content/ view/77650.html>. Acesso em: 16 jan. 2009.
METCALF \& EDDY, Inc. (2002) Wastewater Engineering - Treatment and Reuse. 3 ed. New York: McGraw-Hill Book Co.

NAKAZATO, C.D. (2005) Efeitos da equalização de fluxos sobre o desempenho da estação de tratamento de esgotos de Brasília Norte - ETEB Norte. 151 f. Dissertação (Mestrado em Tecnologia Ambiental e Recursos Hídricos) - Universidade de Brasília, Brasília.

ROCHA, M.T. (2003) Aquecimento global e mercado de carbono: uma aplicação do modelo CERT. 214 f. Tese (Doutorado em Ciências) Universidade de São Paulo, Piracicaba.

ROSAL, M.C.F. (2007) Programação não-linear aplicada à otimização de redes pressurizadas de distribuição de água. $97 \mathrm{f}$. Dissertação (Mestrado em Ciências em Engenharia Civil) - Universidade Federal de Pernambuco, Recife.

UNFCCC. United Nations Framework Convention on Climate Change. Clean Development Mechanism. 2008 in brielf. Disponível em: <http:// unfccc.int/resource/docs/publications/08_cdm_in_brief.pdf $>$. Acesso em: 16 jan. 2009.

UNFCCC. United Nations Framework Convention on Climate Change. Clean Development Mechanism: Programme of activities validation]. Disponível em: <http://cdm.unfccc.int/ProgrammeOfActivities/ Validation/index.html> . Acesso em: 17 jan. 2009.

UNFCCC. United Nations Framework Convention on Climate Change. Waste gases utilisation for Combined Cycle Power Plant in Handan Iron \& Steel Group Co., Ltd. Disponível em: <http://cdm.unfccc.int/Projects/ Validation/DB/M17JEHTGGPCIP6FXW9K6B4LNI1ZRYG/view.html>. Acesso em: 17 jan. 2009 
UNFCCC. United Nations Framework Convention on Climate Change. Methane recovery in wastewater treatment. Disponível em: $\quad<$ http://cdm.unfccc.int/UserManagement/FileStorage/ K3DAOL1H7RB9CN5GMXET4FOWSU26ZY > . Acesso em: 16 nov. 2009.

UNFCCC. United Nations Framework Convention on Climate Change. Methodological tool: tool to calculate the emission factor for an electricity system. Disponível em: <http://cdm.unfccc.int/EB/035/eb35_repan12. pdf >. Acesso em: 16 nov. 2009.

UNFCCC. United Nations Framework Convention on Climate Change. Methodological: Tool to determine project emissions from flaring gases containing methane. Disponível em: <http://cdm.unfccc.int/ methodologies/PAmethodologies/tools/am-tool-06-v1.pdf>. Acesso em: 16 nov. 2009.
UNFCCC. United Nations Framework Convention on Climate Change. Project 0164: Bandeirantes Landfill Gas to Energy Project (BLFGE). Disponível em: <http://cdm.unfccc.int/Projects/DB/DNVCUK1134130255.56>. Acesso em: 8 mai. 2011.

VITOUSEK, P.M. (1994) Beyond global warming: ecology and global change. Ecology, v. 75, n. 7, p. 1861-76.

Von SPERLING, M. (1997) Princípios de tratamento biológico de águas residuárias: Lodos ativados. 2 ed. Belo Horizonte: DESA-UFMG. 428 p.

WEITZ, K.A.; THORNELOE, S.A.; NISHTALA, S.R.; YARKOSKY,S.; ZANNES, M. (2002) The impact of municipal solid waste management on greenhouse gas emissions in the United States. Jornal of the Air \& Waste Management Association, v. 52, n. 9, p. 1000-11. 